\title{
Health literacy of patients admitted for elective surgery
}

\author{
E. S. Koster $^{1}$ • A. Schmidt ${ }^{1}$ • D. Philbert ${ }^{1}$ - E. M. W. van de Garde ${ }^{1,2} \cdot$ M. L. Bouvy ${ }^{1}$
}

Received: 10 May 2016/Accepted: 17 November 2016 / Published online: 6 December 2016

(C) The Author(s) 2016. This article is published with open access at Springerlink.com

\begin{abstract}
Aim Patients with limited health literacy have poorer surgical outcomes. However, current studies assessing the prevalence of limited health literacy in patients expecting surgery are small scale. We aimed to provide insight into the health literacy level of patients undergoing planned surgery.

Subject and Methods Patients aged $\geq 18$ years visiting the preoperative screening department were approached in the waiting area and invited to participate in a brief interview including the Functional Communicative Critical Health Literacy (FCCHL).

Results In total, 225 patients ( $84.9 \%$ response) were studied. Based on the FCCHL, 37.3\% of the patients were classified as having limited health literacy. The mean score in the critical domain $(2.7 \pm 0.9)$ was lower than scores in the functional (3.3 $\pm 0.6)$ and communicative $(3.3 \pm 0.6)$ domains.

Conclusion More than one third of the patients admitted to the hospital for surgery had limited health literacy. Healthcare professionals should be aware of the different health literacy levels and tailor their information provision strategies accordingly.
\end{abstract}

Keywords Health literacy · Communicative $\cdot$ Critical · Functional $\cdot$ FCCHL $\cdot$ Hospital $\cdot$ Surgery

E. S. Koster

e.koster@uu.nl

1 Division of Pharmacoepidemiology and Clinical Pharmacology, Utrecht University, PO Box 800823508 TB,

Utrecht, The Netherlands

2 Department of Clinical Pharmacy, St. Antonius Hospital Nieuwegein, Utrecht, The Netherlands

\section{Introduction}

Health literacy, defined as the ability to obtain, understand and use information in health-related decisions, can be described in terms of functional, communicative and critical skills (Nutbeam 2008, 2009). Functional skills are necessary for reading and writing in order to function in everyday situations, communicative skills are more advanced skills to extract and apply (new) information in different situations, and critical skills are needed for analyzing and reflecting on information or advice.

Several studies have shown that patients with limited health literacy have poorer health outcomes (Berkman et al. 2011). Patients who undergo surgery often receive specific preoperative instructions, e.g., with respect to food and drink restrictions or temporary discontinuation of medication. Chew et al. (2004) showed that patients with limited health literacy were less likely to comply with preoperative instructions, which could lead to delays, cancellation of surgical procedures or even negative surgical outcomes.

To date, only a few small studies have been performed on the prevalence and consequences of limited health literacy in perioperative care for surgical patients (Beitler et al. 2010; Choi 2013; De Oliveira et al. 2015; Gordon and Wolf 2009). Therefore, we aimed to provide insight into the health literacy level of patients admitted to the hospital for elective surgery.

\section{Methods}

\section{Design and setting}

We conducted a cross-sectional study at the preoperative screening department of the St. Antonius Hospital (850-bed teaching hospital) in Nieuwegein, The Netherlands. Before 
planned hospital admission, patients visit this department and receive information about the surgical procedure, anesthesia and the general procedure for hospital admission including preoperative instructions (e.g., food or drink restrictions or medication instructions).

The study protocol was approved by the Institutional Review Board of the Division of Pharmacoepidemiology \& Clinical Pharmacology, Utrecht University, and the local review committee of St. Antonius Hospital, Nieuwegein.

\section{Study population}

Patients aged $\geq 18$ years who were scheduled for surgery and visiting the preoperative screening department were invited to participate in the study. Patients insufficiently proficient in the Dutch language and patients with dementia were excluded from the study. Patients who signed the informed consent form were interviewed to assess their health literacy level. A master pharmacy student of the Utrecht School of Pharmacy performed the interviews.

\section{Data collection}

Data were collected from September-November 2015. The Dutch version of the Functional Communicative Critical Health Literacy (FCCHL) instrument, a validated questionnaire to assess health literacy skills (Nutbeam 2008, 2009; van der Vaart et al. 2012), was used to guide data collection (Ishikawa et al. 2008). The FCCHL measures three aspects of health literacy using 14 questions, namely functional (5 questions), communicative (5 questions) and critical skills (4 questions) (van der Vaart et al. 2012). All questions were scored on a four point Likertscale (1-4) ranging from never perceiving difficulties to often perceiving difficulties. Mean total FCCHL scores and mean sub-scale scores were calculated by summing item scores divided by the total number of items (in total or in the sub-scale), resulting in a score ranging from 1 (low health literacy) to 4 (high health literacy). Based on previous research, patients with scores $\leq 3$ in total or on a sub-scale were defined as having limited health literacy (Fransen et al. 2011). In addition, information about socio-demographic characteristics such as age, gender, educational level and ethnic origin was collected during the interview.

\section{Data analysis}

Descriptive statistics were used to calculate health literacy in total and for the three different sub-scales (functional, communicative and critical). We presented the proportion of patients with an FCCHL mean total and sub-scale score $\leq 3$ (see above). Logistic regression analysis controlling for age, gender, educational level and ethnic background was used to calculate odds ratios and their corresponding 95\% confidence intervals (CIs) for the association between health literacy and patient characteristics. The possibility for a predictive model for limited health literacy was also investigated. All analyses show the odds ratios for limited health literacy compared with adequate health literacy. Data were analyzed using IBM SPSS version 23.0 (IBM Corp., Armonk, NY, USA) for Windows.

\section{Results}

\section{Study population}

In total, 225 patients $(84.9 \%)$ out of 262 invited patients agreed to participate. The most common reasons for nonwillingness to participate were lack of interest in the study $(18.9 \%, \mathrm{n}=7)$ and lack of time $(21.6 \%, \mathrm{n}=8)$. Table 1 shows the study population characteristics. The majority of the participants were of native Dutch origin (84.0\%).

\section{Health literacy skills}

Overall mean scores $\leq 3$ were found in 84 patients $(37.3 \%)$, indicating limited health literacy. For the three different sub-scales, 30.7\% $(\mathrm{n}=69), 31.6 \%(\mathrm{n}=71)$ and $54.7 \%(\mathrm{n}=123)$ scored below the threshold of three in

Table 1 Study population characteristics

\begin{tabular}{ll}
\hline & $\begin{array}{l}\text { Study population } \\
(\mathrm{N}=225)\end{array}$ \\
\hline Female gender, \% (n) & $55.1(124)$ \\
Mean age, years (SD) & $56.4(15.1)$ \\
Ethnicity*, \% (n) & \\
Native Dutch & $87.6(197)$ \\
Western immigrant & $8.4(19)$ \\
Non-Western immigrant & $4.0(9)$ \\
Educational level**, \% (n) & \\
Low & $33.8(76)$ \\
Middle & $36.4(82)$ \\
High & $29.8(67)$ \\
\hline
\end{tabular}

*Ethnic origin was classified into three groups: native (Dutch), nonWestern immigrant [someone whose country of origin is or lies in Turkey, Africa, Latin America or Asia, with the exception of Indonesia (or the former Dutch East Indies) and Japan] or Western immigrant.

**Low educational level was defined as no secondary education (only primary school) or a lower vocational level. Middle was defined as a higher secondary education or intermediate vocational level, and high educational level was defined as a higher vocational or university level. 


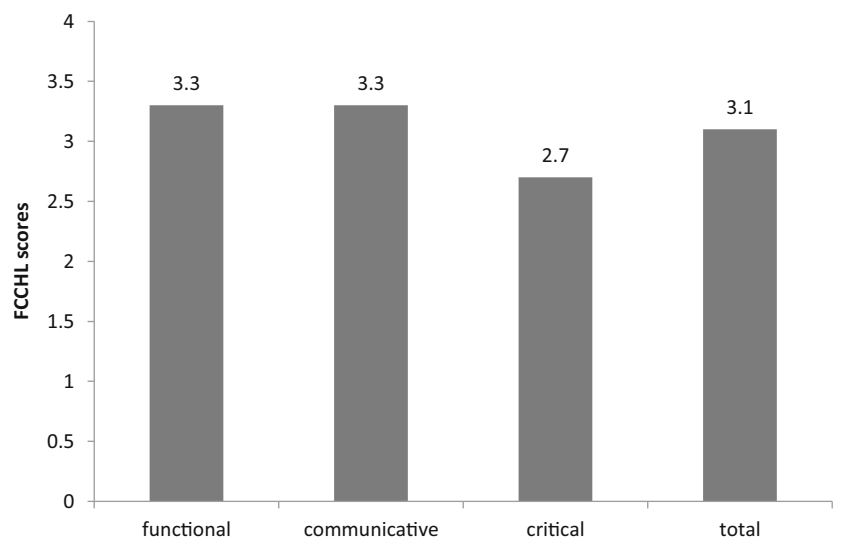

Fig. 1 Mean FCCHL scores

the functional, communicative and critical domains, respectively. Mean FCCHL scores were lowest for critical health literacy (mean score: $2.7 \pm 0.9$ ) compared to functional and communicative health literacy (mean score: $3.3 \pm 0.6$ for both domains) (Fig. 1).

As shown in Table 2, advancing age, non-Western background and lower educational level were significantly associated with limited health literacy $(\mathrm{p}<0.05)$. A separate multivariate logistic regression was performed for each of the three domains (functional, communicative and critical health literacy; Appendix 1 (Tables 3, 4 and 5)). Although not all domains showed the same significant associations, they showed similar trends for characteristics associated with limited health literacy.

Characteristics that were significantly associated in the overall multivariate logistic regression were added to a predictive model for limited health literacy (regression equation: $-2.9+[0.003 *$ age $]+[1.8 *$ non-Western background $]+[0.83 *$ low education level $]+[0.90 *$ middle education level]), which showed a good fit (Hosmer and Lemeshow test $\mathrm{p}=0.74$ ); however, the predictive power of the model was poor (area under the curve: 0.68).

\section{Discussion}

More than one third of patients scheduled for elective surgery were classified as having limited health literacy. The prevalence of limited health literacy found in our study is in line with other studies (van der Heide et al. 2015). Also, as in previous studies, patients scored lowest in the critical domain (Heijmans et al. 2015; Ishikawa et al. 2009). Patients may be able to read and write, but may still be hampered in more complex tasks or decisions as reflected by the lower scores in this domain. Heijmans et al. (2015) reported that mainly communicative and critical health literacy is important for successful disease self-management. Thus, a broad range of skills is necessary for active patient participation and optimal outcomes.

In addition, we demonstrated associations between limited health literacy and demographic factors, e.g., advancing age, lower educational level and non-native (non-Western) background. This is in line with findings reported in the literature (Chew et al. 2004; Koster et al. 2015; van der Heide et al. 2015). However, the predictive power of our model was not very high, suggesting that healthcare professionals cannot solely depend on age, education level and non-Western background to identify patients at risk of having limited health literacy.

One of the strengths of the study is that the health literacy screening was conducted verbally, thereby also enabling patients who experience difficulties in reading or writing, and thus might have limited functional health literacy, to participate. In addition, selection bias is unlikely due to the high response rate $(>80 \%)$. Many previous studies have used health literacy measurement instruments that focus solely on functional skills, e.g., reading comprehension, while the FCCHL we used in this study also includes assessment of communicative
Table 2 Patient characteristics associated with limited health literacy

\begin{tabular}{llllll}
\hline & $\begin{array}{l}\text { Adequate health } \\
\text { literacy* } \\
\mathrm{N}=141\end{array}$ & $\begin{array}{l}\text { Limited health } \\
\text { literacy* } \\
\mathrm{N}=84\end{array}$ & $\begin{array}{l}\text { Crude OR } \\
(95 \% \mathrm{CI})\end{array}$ & $\begin{array}{l}\text { Adjusted** OR } \\
(95 \% \mathrm{CI})\end{array}$ & $p$ \\
\hline $\begin{array}{l}\text { Age, mean (SD) } \\
\text { Gender, \% (n) }\end{array}$ & $54.6(14.9)$ & $59.4(15.1)$ & $1.02(1.0-1.0)$ & $1.02(1.0-1.0)$ & 0.03 \\
$\quad \begin{array}{l}\text { Male } \\
\text { Female }\end{array}$ & $40.4(57)$ & $52.4(44)$ & $1.6(0.9-2.8)$ & $1.6(0.9-2.9)$ & 0.12 \\
$\begin{array}{l}\text { Educational level, \% (n) } \\
\text { Low }\end{array}$ & $59.6(84)$ & $47.6(40)$ & REF & REF & REF \\
$\quad$ Middle & $29.1(41)$ & $41.7(35)$ & $2.7(1.3-5.6)$ & $2.5(1.1-5.3)$ & 0.02 \\
$\quad$ High & $34.8(49)$ & $39.3(33)$ & $2.1(1.1-4.4)$ & $2.5(1.2-5.4)$ & 0.02 \\
Non-Western & $36.2(51)$ & $19.0(16)$ & REF & REF & REF \\
background, \% (n) & $4.3(6)$ & $15.5(13)$ & $4.1(1.5-11.3)$ & $6.0(2.1-17.8)$ & 0.001 \\
\hline
\end{tabular}

*Adequate health literacy was defined as a total FCCHL score $>3$ and limited health literacy as a total FCCHL score $\leq 3$

**Adjusted for age, gender, educational level and background

$\mathrm{REF}=$ reference category 
and critical skills and thus gives insight into the broader range of health literacy skills. However, as the FCCHL is a subjective instrument based on self-reporting, it may lead to observations that differ from actual patient behavior. In real-life situations people may experience even more difficulties with certain tasks, in which case our results underestimate the problem of limited health literacy.

Low health literacy has previously been associated with poorer surgical outcomes and misunderstanding of information (Koster et al. 2015). Inadequate understanding of information or instructions may also have negative consequences for the hospital in terms of delayed or cancelled surgical procedures. This study shows that a considerable proportion of patients who are undergoing surgery have limited health literacy.

The first step in tackling this problem is creating awareness among healthcare professionals. They should take into account the different skill levels of their patients and tailor their information and communication strategies to suit patients' individual needs. Many current health literacy interventions consist of handing out (additional) written information or providing information in another language (Taggart et al. 2012; Wali et al. 2015). However, patients with limited health literacy may have more complex problems, as shown by the lower scores in the critical domain in our study, hampering active patient participation during consultations and treatment decisions. Therefore, healthcare providers should ensure they provide easy-to-understand information and instructions. Checking comprehension using teach-back methods, for example, can reduce misunderstandings and potentially prevent negative health outcomes (Samuels-Kalow et al. 2016).

In conclusion, this study shows that a considerable proportion of patients scheduled for surgery have limited health literacy. Patients scored lowest in the critical domain, which may have consequences for self-management. Healthcare providers involved in preoperative screening should actively identify patients with poor health literacy and should adapt their information and instructions for these patients.

Acknowledgments The authors would like to thank the staff members of the preoperative screening department of St. Antonius Hospital, Nieuwegein, for their cooperation, with special thanks to Kees de Jong for his assistance and advice. This research did not receive any specific grant from funding agencies in the public, commercial or not-for-profit sectors.

Compliance with ethical standards No external funding was received for this study.

All procedures performed in studies involving human participants were in accordance with the ethical standards of the institutional and/or national research committee and with the 1964 Helsinki Declaration and its later amendments or comparable ethical standards.

The study protocol was approved by the Institutional Review Board of the Division of Pharmacoepidemiology \& Clinical Pharmacology, Utrecht University, and the local review committee of St. Antonius Hospital, Nieuwegein.

Conflict of Interest Authors Koster, Schmidt, Philbert, van de Garde and Bouvy declare that there are no conflicts of interest relevant for this study.

\section{Appendix 1}

Table 3 Multivariate logistic regression for FCCHL subscale Functional Health Literacy

\begin{tabular}{llllll}
\hline & $\begin{array}{l}\text { Adequate health } \\
\text { literacy* } \\
\mathrm{N}=141\end{array}$ & $\begin{array}{l}\text { Limited health } \\
\text { literacy* } \\
\mathrm{N}=84\end{array}$ & $\begin{array}{l}\text { Crude OR } \\
\text { (95\% CI })\end{array}$ & $\begin{array}{l}\text { Adjusted** OR } \\
\text { (95\% CI) }\end{array}$ & $p$ \\
\hline $\begin{array}{l}\text { Age, mean (SD) } \\
\text { Gender, \% (n) }\end{array}$ & $55.2(15.2)$ & $59.0(14.8)$ & $1.02(1.0-1.0)$ & $1.03(1.0-1.1)$ & 0.03 \\
$\quad \begin{array}{l}\text { Male } \\
\text { Female }\end{array}$ & $42.3(66)$ & $50.7(35)$ & $1.4(0.8-2.5)$ & $1.3(0.7-2.5)$ & 0.36 \\
$\begin{array}{l}\text { Educational level, \% (n) } \\
\text { Low }\end{array}$ & $57.7(90)$ & $49.3(34)$ & REF & REF & REF \\
$\quad 32.7(51)$ & $36.2(25)$ & $1.6(0.7-3.3)$ & $1.3(0.6-2.9)$ & 0.50 \\
$\quad \begin{array}{l}\text { Middle } \\
\text { High }\end{array}$ & $34.6(54)$ & $40.6(28)$ & $1.7(0.8-3.4)$ & $1.9(0.9-4.1)$ & 0.10 \\
$\begin{array}{l}\text { Non-Western } \\
\text { background, \% (n) }\end{array}$ & $32.7(51)$ & $23.2(16)$ & REF & REF & REF \\
\hline
\end{tabular}

*Adequate health literacy was defined as a total FCCHL score $>3$ and limited health literacy as a total FCCHL score $\leq 3$

**Adjusted for age, gender, educational level and background 
Table 4 Multivariate logistic regression for FCCHL subscale Communicative Health Literacy

\begin{tabular}{llllll}
\hline & $\begin{array}{l}\text { Adequate health } \\
\text { literacy* } \\
\mathrm{N}=141\end{array}$ & $\begin{array}{l}\text { Limited health } \\
\text { literacy* } \\
\mathrm{N}=84\end{array}$ & $\begin{array}{l}\text { Crude OR } \\
(95 \% \mathrm{CI})\end{array}$ & $\begin{array}{l}\text { Adjusted** OR } \\
(95 \% \mathrm{CI})\end{array}$ & $p$ \\
\hline Age, mean (SD) & $54.4(14.6)$ & $60.6(15.4)$ & $\begin{array}{c}1.03 \\
(1.0-1.1)\end{array}$ & $1.03(1.0-1.0)$ & 0.04 \\
Gender, \% (n) & & & $1.8(1.0-3.2)$ & $1.7(0.9-3.2)$ & 0.08 \\
$\quad$ Male & $40.3(62)$ & $54.9(39)$ & $\mathrm{REF}$ & $\mathrm{REF}$ & $\mathrm{REF}$ \\
Female & $59.7(92)$ & $45.1(32)$ & $3.5(1.6-7.6)$ & $3.1(1.4-7.0)$ & 0.007 \\
$\begin{array}{l}\text { Educational level, \% (n) } \\
\text { Low }\end{array}$ & $27.9(43)$ & $46.5(33)$ & $2.1(1.0-4.6)$ & $2.5(1.1-5.5)$ & 0.03 \\
$\quad \begin{array}{l}\text { Middle } \\
\text { High }\end{array}$ & $36.4(56)$ & $36.6(26)$ & $\mathrm{REF}$ & $\mathrm{REF}$ & $\mathrm{REF}$ \\
$\begin{array}{l}\text { Non-Western } \\
\text { background, \% (n) }\end{array}$ & $35.7(55)$ & $16.9(12)$ & $2.1(0.8-5.4)$ & $3.0(1.1-8.4)$ & 0.04 \\
\hline
\end{tabular}

*Adequate health literacy was defined as a total FCCHL score $>3$ and limited health literacy as a total FCCHL score $\leq 3$

**Adjusted for age, gender, educational level and background
Table 5 Multivariate logistic regression for FCCHL subscale Critical Health Literacy

\begin{tabular}{|c|c|c|c|c|c|}
\hline & $\begin{array}{l}\text { Adequate health } \\
\text { literacy* } \\
\mathrm{N}=141\end{array}$ & $\begin{array}{l}\text { Limited health } \\
\text { literacy* } \\
\mathrm{N}=84\end{array}$ & $\begin{array}{l}\text { Crude OR } \\
(95 \% \mathrm{CI})\end{array}$ & $\begin{array}{l}\text { Adjusted** OR } \\
(95 \% \mathrm{CI})\end{array}$ & $p$ \\
\hline Age, mean (SD) & $52.8(14.4)$ & $59.4(15.1)$ & $1.03(1.0-1.1)$ & $1.03(1.0-1.1)$ & 0.05 \\
\hline \multicolumn{6}{|l|}{ Gender, \% (n) } \\
\hline Male & $39.2(40)$ & $49.6(61)$ & $1.5(0.9-2.6)$ & $1.4(0.8-2.4)$ & 0.30 \\
\hline Female & $60.8(62)$ & $50.4(62)$ & REF & REF & $\mathrm{REF}$ \\
\hline \multicolumn{6}{|l|}{ Educational level, \% (n) } \\
\hline Low & $29.1(41)$ & $41.7(35)$ & $2.1(1.1-4.1)$ & $1.7(0.8-3.4)$ & 0.16 \\
\hline Middle & $34.8(49)$ & $39.3(33)$ & $1.3(0.7-2.4)$ & $1.4(0.7-2.8)$ & 0.30 \\
\hline High & $36.2(51)$ & $19.0(16)$ & REF & REF & REF \\
\hline $\begin{array}{l}\text { Non-Western } \\
\quad \text { background, \% (n) }\end{array}$ & $4.9(5)$ & $11.4(14)$ & $2.5(0.9-7.2)$ & $3.5(1.2-10.5)$ & 0.03 \\
\hline
\end{tabular}

*Adequate health literacy was defined as a total FCCHL score $>3$ and limited health literacy as a total FCCHL score $\leq 3$

**Adjusted for age, gender, educational level and background
Open Access This article is distributed under the terms of the Creative Commons Attribution 4.0 International License (http:// creativecommons.org/licenses/by/4.0/), which permits unrestricted use, distribution, and reproduction in any medium, provided you give appropriate credit to the original author(s) and the source, provide a link to the Creative Commons license, and indicate if changes were made.

\section{References}

Beitler JJ, Chen AY, Jacobson K, Owens A, Edwards M, Johnstone PA (2010) Health literacy and health care in an inner-city, total laryngectomy population. Am J Otolaryngol 31(1):29-31
Berkman ND, Sheridan SL, Donahue KE, Halpern DJ, Crotty K (2011) Low health literacy and health outcomes: an updated systematic review. Ann Intern Med 155(2):97-107

Chew LD, Bradley KA, Flum DR, Cornia PB, Koepsell TD (2004) The impact of low health literacy on surgical practice. Am J Surg 188(3):250-3

Choi J (2013) Older adults' perceptions of pictograph-based discharge instructions after hip replacement surgery. J Gerontol Nurs 39(7): $48-54$

De Oliveira GS, Jr MCRJ, Wolf MS, Holl J (2015) The impact of health literacy in the care of surgical patients: a qualitative systematic review. BMC Surg 15(86):015-0073-6

Fransen MP, Van Schaik TM, Twickler TB, Essink-Bot ML (2011) Applicability of internationally available health 
literacy measures in the Netherlands. J Health Commun 16(Suppl 3):134-49

Gordon EJ, Wolf MS (2009) Health literacy skills of kidney transplant recipients. Prog Transplant 19(1):25-34

Heijmans M, Waverijn G, Rademakers J, van der Vaart R, Rijken M (2015) Functional, communicative and critical health literacy of chronic disease patients and their importance for self-management. Patient Educ Couns 98(1):41-8

Ishikawa $\mathrm{H}$, Takeuchi T, Yano E (2008) Measuring functional, communicative, and critical health literacy among diabetic patients. Diabetes Care 31(5):874-9

Ishikawa H, Yano E, Fujimori S, Kinoshita M, Yamanouchi T, Yoshikawa M, Yamazaki Y, Teramoto T (2009) Patient health literacy and patient-physician information exchange during a visit. Fam Pract 26(6):517-23

Koster ES, Philbert D, Bouvy ML (2015) Health literacy among pharmacy visitors in the Netherlands. Pharmacoepidemiol Drug Saf 24(7): $716-21$

Nutbeam D (2008) The evolving concept of health literacy. Soc Sci Med 67(12):2072-8
Nutbeam D (2009) Defining and measuring health literacy: what can we learn from literacy studies? Int J Public Health 54(5):303-5

Samuels-Kalow M, Hardy E, Rhodes K, Mollen C (2016) Like a dialogue. Teach-back in the emergency department. Patient Educ Couns 99(4):549-54

Taggart J, Williams A, Dennis S, Newall A, Shortus T, Zwar N, DenneyWilson E, Harris MF (2012) A systematic review of interventions in primary care to improve health literacy for chronic disease behavioral risk factors. BMC Fam Prac 13:49

van der Heide I, Heijmans M, Schuit AJ, Uiters E, Rademakers J (2015) Functional, interactive and critical health literacy: Varying relationships with control over care and number of GP visits. Patient Educ Couns 98(8):998-1004

van der Vaart R, Drossaert CH, Taal E, ten Klooster PM, HilderinkKoertshuis RT, Klaase JM, van de Laar MA (2012) Validation of the Dutch functional, communicative and critical health literacy scales. Patient Educ Couns 89(1):82-81

Wali H, Hudani Z, Wali S, Mercer K, Grindrod K (2015) A systematic review of interventions to improve medication information for low health literate populations. Res Social Adm Pharm 